Pacific Journal of Mathematics

ON THE GENERALIZED DIFFERENCE POLYNOMIALS 


\section{ON THE GENERALIZED DIFFERENCE POLYNOMIALS}

\section{Panaitopol and D. Stefănescu}

We study some factorization properties of a family of polynomials which includes the generalized difference polynomials. We deduce new irreducibility criteria for polynomials in two variables with coefficients in an algebraically closed field. We also obtain new proofs for the irreducibility criteria of Ehrenfeucht and Angermüller.

Let $k$ be a commutative algebraically closed field. A polynomial in two variables $P(X, Y) \in k[X, Y]$ is called a difference polynomial if $P(X, Y)=f(X)-g(Y)$, where $f, g \in k[X] \backslash k$.

A. Ehrenfeucht [6] and H. Tverberg [11] studied a case of irreducibility of the difference polynomials and A. Schinzel [10] established conditions for the factorization of the difference polynomials. L. A. Rubel and S. S. Abhyankar [2], L. A. Rubel, A. Schinzel and H. Tverberg [8] and G. Angermüller [3] studied some factorization and irreducibility conditions of the larger class of the generalized difference polynomials

$$
Q(X, Y)=c Y^{n}+\sum_{i=1}^{n} P_{i}(X) Y^{n-i},
$$

where $c \in k \backslash\{0\}, n \in \mathbb{N}^{*}, \operatorname{deg} P_{n}(X)=m \geq 1$ and $\operatorname{deg} P_{i}(X)<m i / n$ for every $i, 1 \leq i \leq n-1$.

In this paper we study factorization properties of polynomials of the form

$$
\text { (**) } \quad F(X, Y)=c Y^{n}+\sum_{i=1}^{n} P_{i}(X) Y^{n-i} \text {, }
$$

where $c \in k \backslash\{0\}, P_{i}(X) \in k[X], n \geq 1$.

The family of the polynomials $(* *)$ includes the class of the generalized difference polynomials $(*)$. We introduce a rational number $p_{Y}(F)$ associated with a polynomial $F(X, Y) \in k[X, Y]$ that satisfies $(* *)$. We shall establish some properties of $p_{Y}(F)$ using a Newton polygon argument. We deduce irreducibility criteria for the polynomials $(* *)$. We also obtain new proofs of the criteria of Ehrenfeucht and Angermüller. 
Definition. Let $X, Y$ be two indeterminates over $k$ and let

$$
F(X, Y)=c Y^{n}+\sum_{i=1}^{n} P_{i}(X) Y^{n-i} \in k[X, Y],
$$

where $c \in k \backslash\{0\}, n \geq 1, P_{i}(X) \in k[X]$.

We call the degree index of the polynomial $F(X, Y)$ the rational number

$$
p_{Y}(F)=\max \left\{\frac{\operatorname{deg} P_{i}}{i} ; 1 \leq i \leq n\right\} .
$$

REMARKS. (i) $p_{Y}(F)=0$ if and only if $F(X, Y) \in k[Y]$.

(ii) If

$$
p_{Y}(F)=\frac{\operatorname{deg} P_{n}}{n} \text { and } p_{Y}(F)>\max \left\{\frac{\operatorname{deg} P_{i}}{i} ; 1 \leq i \leq n-1\right\}
$$

then $F(X, Y)$ is a generalized difference polynomial.

THEOREM 1. Let

$$
F(X, Y)=c Y^{n}+\sum_{i=1}^{n} P_{i}(X) Y^{n-1} \in k[X, Y],
$$

where $c \in k \backslash\{0\}, P_{i}(X) \in k[X], n \geq 1$. If $F=F_{1} F_{2}$, with $F_{1}, F_{2} \in$ $k[X, Y] \backslash k$, then $p=\max \left(p_{1}, p_{2}\right)$, where $p=p_{Y}(F), p_{1}=p_{Y}\left(F_{1}\right)$, $p_{2}=p_{Y}\left(F_{2}\right)$.

Proof. We shall prove that $p$ can be obtained as a suitable number associated with the polynomial $G(X, Y):=Y^{n} F\left(X^{-1}, Y^{-1}\right) \in$ $k((X))[Y]$. ( $G$ is a polynomial in $Y$ with the coefficients meromorphic formal power series in $X$.)

Let

$$
G(X, Y)=\sum_{i=0}^{n} H_{i}(X) Y^{i} \in k((X))[Y],
$$

where $H_{i}(X) \in k((X))$. Let $r_{i}=\operatorname{ord}_{X} H_{i}(X)$ and let

$$
e(G)=\max \left(\frac{r_{0}-r_{1}}{1}, \frac{r_{0}-r_{2}}{2}, \ldots, \frac{r_{0}-r_{n}}{n}\right) .
$$

But

$$
G(X, Y)=P_{n}\left(\frac{1}{X}\right) Y^{n}+P_{n-1}\left(\frac{1}{X}\right) Y^{n-1}+\cdots+P_{1}\left(\frac{1}{X}\right) Y+c .
$$


Hence $r_{0}=0$ and $r_{i}=\operatorname{ord}_{X} P_{i}\left(\frac{1}{X}\right)=-\operatorname{deg}\left(P_{i}\right)$ for $i=1,2, \ldots, n$. Therefore $r_{0}-r_{1}=0-\left(-\operatorname{deg}\left(P_{i}\right)\right)=\operatorname{deg}\left(P_{i}\right)$ and it follows that

$$
e(G)=p_{Y}(F) \text {. }
$$

If the characteristic of the field $k$ is zero or is positive and does not divide the degree $n$ of the polynomial $G(X, Y)$ then $e(G)$ is the smallest exponent of a Puiseux series

$$
y(X)=\sum_{i} c_{i} X^{i} \in \bigcup_{m=1}^{\infty} k\left(\left(X^{1 / m}\right)\right) \quad \text { such that } G(X, y)=0 .
$$

(Such a series exists because $k$ is algebraically closed and the characteristic of $k$ does not divide $n$.)

If the characteristic of $k$ is positive and divides $n$ then a root $y(X)$ of the equation $G(X, y)=0$ is not necessary a Puiseux series, as it was remarked by $C$. Chevalley in [4], p. 64. In this case a root of the equation $G(X, y)=0$ is a general power series $y(X)=$ $\sum_{i \in S(f)} c_{i} X^{i} \in k\left(\left(T^{\mathbb{Q}}\right)\right)$, where the support $S(f)$ is a well ordered subset of $\mathbb{Q}$. Let $i_{0}$ be the smallest of the exponents of $y(X)$. Then $i_{0}$ can be obtained with a Newton polygon argument (cf. [7] pp. 4248) as

$$
i_{0}=\max \left(\frac{r_{0}-r_{1}}{1}, \frac{r_{0}-r_{2}}{2}, \ldots, \frac{r_{0}-r_{n}}{n}\right) .
$$

Indeed, it suffices to remark that the determination of $i_{0}$ above does not depend on the characteristic. Therefore $i_{0}=e(G)$.

Let $G_{1}(X, Y), G_{2}(X, Y) \in k((X))[Y]$ corresponding to the polynomials $F_{1}$ and $F_{2}$ respectively. From a result of $G$. Dumas relative to the Newton polygon of the product of two polynomials ([5], pp. 216-217) it follows that $e(G)=\max \left(e\left(G_{1}\right), e\left(G_{2}\right)\right)$. From (1) we deduce that $p=\max \left(p_{1}, p_{2}\right)$.

Proposition 2. Let

$$
F(X, Y)=c Y^{n}+\sum_{i=1}^{n} P_{i}(X) Y^{n-i} \in k[X, Y],
$$

where $c \in k^{*}, n \geq 1$ and let $m=\operatorname{deg} P_{n}(X)$. Let us suppose that $p_{Y}(F)=m / n$. If $\bar{F}=F_{1} F_{2}$, with $F_{1}, F_{2} \in k[X, Y] \backslash k$ then $p_{Y}(F)=$ $p_{Y}\left(F_{1}\right)=p_{Y}\left(F_{2}\right)$.

Proof. Let

$$
F_{i}(X, Y)=c_{i} Y^{n_{\iota}}+\sum_{j=1}^{n_{t}} P_{i j}(X) Y^{n_{\imath}-j}
$$


where $c_{i} \in k^{*}, P_{i j}(X) \in k[X]$ and let $m_{i}=\operatorname{deg} P_{i n_{i}}(i=1,2)$. Then $n_{1}+n_{2}=n, m_{1}+m_{2}=m$.

From Theorem 1 it follows that

$$
\frac{m_{1}}{n_{1}} \leq \frac{m}{n} \quad \text { and } \quad \frac{m_{2}}{n_{2}} \leq \frac{m}{n}
$$

But

$$
\frac{m}{n}=\frac{m_{1}+m_{2}}{n_{1}+n_{2}}
$$

We deduce that $m_{2} n_{1} \geq m_{1} n_{2} \geq m_{2} n_{1}$, and hence $m_{2} n_{1}=m_{1} n_{2}$. Therefore

$$
\frac{m}{m_{2}}=\frac{m_{1}+m_{2}}{m_{2}}=\frac{n_{1}+n_{2}}{n_{2}}=\frac{n}{n_{2}} \text {. }
$$

It follows that $m / n=m_{2} / n_{2}$, and hence $p_{Y}\left(F_{2}\right)=p_{Y}(F)$. In the same way we deduce that $p_{Y}\left(F_{1}\right)=p_{Y}(F)$.

Corollary 3. Let

$$
F(X, Y)=c Y^{n}+\sum_{i=1}^{n} P_{i}(X) Y^{n-i} \in k[X, Y],
$$

where $c \in k^{*}, P_{i}(X) \in k[X], n \geq 1$ and let $m=\operatorname{deg} P_{n}(X)$. If $p_{Y}(F)=m / n$ and $(m, n)=1$ then the polynomial $F(X, Y)$ is irreducible in $k[X, Y]$.

Proof. Let us suppose that there are $F_{1}, F_{2} \in k[X, Y] \backslash k$ such that $F=F_{1} F_{2}$. We suppose $F_{1}, F_{2}$ expressed as in the proof of the former proposition.

Because $p_{Y}(F)=p_{Y}\left(F_{1}\right)=p_{Y}\left(F_{2}\right)=m / n$ there is $i \in\{1,2, \ldots$, $\left.n_{1}\right\}$ such that

$$
\frac{\operatorname{deg}\left(P_{1 i}\right)}{i}=\frac{m}{n}
$$

Therefore $i m=n \cdot \operatorname{deg}\left(P_{1 i}\right)$. Since $(m, n)=1$ there is $s \in \mathbb{N}^{*}$ such that $i=s n$. It follows that $i=n_{1}=n$ and $\operatorname{deg}\left(P_{1 i}\right)=\operatorname{deg}\left(P_{1 n_{1}}\right)=$ $\operatorname{deg}\left(P_{1 n}\right)=m$. Therefore $F_{2}(X, Y) \in k[X]$ and we deduce that $P_{n}(X)=P_{1 n}(X) F_{2}(X, Y)$. We conclude that $F_{2}(X, Y) \in k$, a contradiction. It follows that $F(X, Y)$ is irreducible in $k[X, Y]$.

REMARKS. (i) If the characteristic of $k$ does not divide $n$ one can prove Corollary 3 using the Newton-Puiseux expansion theorem [1], 5.14 . 
(ii) The class of the polynomials

$$
\begin{array}{r}
F(X, Y)=c Y^{n}+\sum_{i=1}^{n} P_{i}(X) Y^{n-i} \in k[X, Y], \quad c \in k^{*}, \\
P_{i}(X) \in k[X], \quad n \geq 1
\end{array}
$$

such that

$$
p_{Y}(F)=\frac{\operatorname{deg}\left(P_{n}\right)}{n}
$$

includes the family of the generalized difference polynomials. Therefore Corollary 3 establishes an irreducibility criterion for the generalized difference polynomials.

LEMMA 4. Let

$F(X, Y)=c Y^{n}+\sum_{i=1}^{n} P_{i}(X) Y^{n-1} \in k[X, y], \quad c \in k^{*}, \quad P_{i}(X) \in k[X]$ and let $f \in[X] \backslash k, g \in k[Y] \backslash k$. Then

$$
p_{Y}(F(f, g))=\frac{\operatorname{deg}(f)}{\operatorname{deg}(g)} \cdot p_{Y}(F) .
$$

Proof. Let $u=\operatorname{deg}(f), v=\operatorname{deg}(g)$ and $H(X, Y)=F(f(X), g(Y))$. Then

$$
\begin{aligned}
H(X, Y)= & c[g(Y)]^{n}+P_{1}(f(X))[g(Y)]^{n-1} \\
& +\cdots+P_{n-1}(f(X)) g(Y)+P_{n}(f(X)) .
\end{aligned}
$$

Because

$$
\frac{\operatorname{deg}\left[P_{i}(f(X))\right]}{i v} \geq \frac{\operatorname{deg}\left[P_{i}(f(X))\right]}{s} \text { for } i v \leq s \leq n v
$$

it follows that

$$
p_{Y}(G)=\max \left\{\frac{\operatorname{deg} P_{i}(f)}{i v} ; 1 \leq i \leq n\right\} .
$$

But $\operatorname{deg} P_{i}(f)=u \cdot \operatorname{deg}\left(P_{i}\right)$. Therefore

$$
p_{Y}(H)=\frac{u}{v} \cdot p_{Y}(F)=\frac{\operatorname{deg}(f)}{\operatorname{deg}(g)} \cdot p_{Y}(F) .
$$

COROllary 5. Let

$$
\begin{array}{r}
F(X, Y)=c Y^{n}+\sum_{i=1}^{n} P_{i}(X) Y^{n-i} \in k[X, Y], \quad c \in k^{*}, \\
P_{i}(X) \in k[X], \quad n \geq 1
\end{array}
$$


such that $m=\operatorname{deg}\left(P_{n}\right) \geq 1$ and $p_{Y}(F)=m / n$. If $f \in k[X] \backslash k$ and $g \in k[X] \backslash k$ are such that $(m \cdot \operatorname{deg}(f), n \cdot \operatorname{deg}(g))=1$ then the polynomial $F(f, g)$ is irreducible in $k[X, Y]$.

Proof. Let $H(X, Y)=F(f, g)$. From the above lemma it follows that $p_{Y}(G)=m \cdot \operatorname{deg}(f) / n \cdot \operatorname{deg}(g)$. From Corollary 3 it follows that $F(f, g)$ is irreducible in $k[X, Y]$.

REMARK. Corollary 5 was obtained by G. Angermüller in [3] with different methods in the special case $F(X, Y)$ is a generalized difference polynomial.

THEOREM 6. Let

$$
\begin{array}{r}
F(X, Y)=c Y^{n}+\sum_{i=1}^{n} P_{i}(X) Y^{n-i} \in k[X, Y], \quad c \in k^{*}, \\
P_{i}(X) \in k[X], \quad n \geq 1
\end{array}
$$

and let $a=\operatorname{deg}_{X} F(X, Y)$. If $p_{Y}(F)=a / b,(a, b)=1$, then the polynomial $F(X, Y)$ is irreducible in $k[X, Y]$ or it has a factor from $k[Y]$.

Proof. Let us suppose that there are $F_{1}, F_{2} \in k[X, Y] \backslash k$ such that $F=F_{1} F_{2}$. Let

$$
\begin{gathered}
F_{i}(X, Y)=c_{i} Y^{n_{i}}+\sum_{j=1}^{n_{l}} P_{i j}(X) Y^{n_{i}-j} \in k[X, Y], \quad c_{i} \in k^{*}, \\
P_{i j}(X) \in k[X] \quad(i=1,2) .
\end{gathered}
$$

From Theorem 1 it follows that we may suppose that $p_{Y}\left(F_{1}\right)=$ $p_{Y}(F)$. Hence there is $j \in\left\{1,2, \ldots, n_{1}\right\}$ such that $\operatorname{deg}\left(P_{1 j}\right) / j=$ $a / b$, i.e. $a i=b \cdot \operatorname{deg}\left(P_{1 j}\right)$.

Since $(a, b)=1$ it follows $a$ divides $\operatorname{deg}\left(P_{1 j}\right)$. But $0 \leq \operatorname{deg}\left(P_{1 j}\right) \leq$ $\operatorname{deg}_{X}(F)=a$. Therefore $\operatorname{deg}\left(P_{1 j}\right)=0$ or $a$.

If $\operatorname{deg}\left(P_{1 j}\right)=0$ then $p_{Y}\left(F_{1}\right)=0$; hence $p_{Y}(F)=0$ and it follows that $F(X, Y) \in k[Y]$.

If $\operatorname{deg}\left(P_{1 j}\right)=a$ then $\operatorname{deg}_{X}\left(F_{2}\right)=0$. Therefore $F_{2}$ is a polynomial from $k[Y]$.

If follows that $F(X, Y)$ is irreducible or has a factor from $k[Y]$.

REMARKS. (i) If the polynomial $F(X, Y)$ has a factor from $k[Y]$ then this factor is the greatest common divisor of the polynomials 
$Q_{i} \in k[Y]$ such that

$$
F(X, Y)=\sum_{i=0}^{a} Q_{i}(Y) X^{a-i} .
$$

(ii) If $p_{Y}(F)=m / n$, where $m=\operatorname{deg}\left(P_{n}\right)$, then $m / n \geq \operatorname{deg}\left(P_{i}\right) / i$ for every $i=1,2, \ldots, n$. Hence $m \geq(n / i) \cdot \operatorname{deg} P_{i} \geq \operatorname{deg} P_{i}$ and it follows that $m=a=\operatorname{deg}_{X}(F)$. Therefore the class of the generalized difference polynomials is contained in the family of the polynomials satisfying the assumptions from Theorem 6.

COROllary 7. Let

$$
F(X, Y)=c Y^{n}+\sum_{i=1}^{n} P_{i}(X) Y^{n-i} \in k[X, Y],
$$

where $c \in k^{*}, P_{i}(X) \in k[X], n \geq 1$, let $a=\operatorname{deg}_{X} F(X, Y)$ and $f \in$ $k[X] \backslash k, g \in k[X] \backslash k$. If $p_{Y}(F)=a / b$ and $(a \cdot \operatorname{deg}(f), b \cdot \operatorname{deg}(g))=1$ then $F(f, g)$ is irreducible in $k[X, Y]$ or it has a factor from $k[Y]$.

Proof. Let $u=\operatorname{deg}(f), v=\operatorname{deg}(g)$ and $H(X, Y)=F(f(X), g(Y))$. From Lemma 4 it follows that $p_{Y}(H)=u a / v b$. Since $\operatorname{deg}_{X}(H)=$ $\operatorname{deg}(f) \cdot \operatorname{deg}_{X}(F)=u a$ and $(u a, v b)=1$ we conclude by Theorem 6 .

\section{REFERENCES}

[1] S. S. Abhyankar, Expansion Techniques in Algebraic Geometry, Tata Institute, Bombay (1977).

[2] S. S. Abhyankar and L. A. Rubel, Every difference polynomial has a connected zero-set, J. Indian Math. Soc., 43 (1979), 69-78.

[3] G. Angermüller, A generalization of Ehrenfeucht's irreducibility criterion preprint, Univ. Erlangen, (1985), 1-8.

[4] C. Chevalley, Algebraic Functions of One Variable, Amer. Math. Soc. Math. Surv., 6 (1951).

[5] G. Dumas, Irréductibilité des polynomes à coefficients rationnels, J. de Math. ( $6^{e}$ série), 2 (1906), 191-258.

[6] A. Ehrenfeucht, Kryterium absolutnej nierozkladalnosci wielomianow, Prace Mat., 2 (1958), 167-169.

[7] K. Hensel and G. Landsberg, Theorie der algebraischen Funktionen einer Variabeln, Teubner, Leipzig (1902).

[8] L. A. Rubel, A. Schinzel, and H. Tverberg, On difference polynomials and hereditary irreducible polynomials, J. Number Theory, 12 (1980), 230-235.

[9] A. Schinzel, Reducibility of polynomials in several variables, Bull. Polon. Ac. Sc-Ser. Math., 11 (1963), 633-638.

[10] _ Reducibility of polynomials of the form $f(X)-g(Y)$, Colloq. Math., 18 (1967), 213-218. 
[11] H. Tverberg, A remark on Ehrenfeucht's criterion for irreducibility of polynomials, Prace Mat., 18 (1964), 117-118.

Received July 28, 1988.

UNIVERSITY OF BUCHAREST

STR. ACADEMiEI

14 BUCHAREST, RoMANIA

AND

UNIVERSITY OF BUCHAREST

P.O. Box 52-11

BUChAREST-MAGURELE, RoMANIA 


\section{PACIFIC JOURNAL OF MATHEMATICS EDITORS}

\author{
V. S. VARADARAJAN \\ (Managing Editor) \\ University of California \\ Los Angeles, CA 90024-1555-05 \\ Herbert Clemens \\ University of Utah \\ Salt Lake City, UT 84112 \\ ThOMAs ENRIGHT \\ University of California, San Diego \\ La Jolla, CA 92093
}

R. FINN

Stanford University

Stanford, CA 94305

HeRmanN FlaschKa

University of Arizona

Tucson, AZ 85721

VAUGHAN F. R. JoNES

University of California

Berkeley, CA 94720

SteVen KerCKhofF

Stanford University

Stanford, CA 94305
ROBION KIRBY

University of California

Berkeley, CA 94720

C. C. Moore

University of California

Berkeley, CA 94720

HAROLD STARK

University of California, San Diego

La Jolla, CA 92093

\section{ASSOCIATE EDITORS}
R. ARENS
E. F. BECKENBACH
B. H. NeumanN
F. Wolf
K. YoshidA
(1906-1982)
(1904-1989)

\section{SUPPORTING INSTITUTIONS}

UNIVERSITY OF ARIZONA
UNIVERSITY OF BRITISH COLUMBIA
CALIFORNIA INSTITUTE OF TECHNOLOGY
UNIVERSITY OF CALIFORNIA
MONTANA STATE UNIVERSITY
UNIVERSITY OF NEVADA, RENO
NEW MEXICO STATE UNIVERSITY
OREGON STATE UNIVERSITY
UNIVERSITY OF ARIZONA
UNIVERSITY OF BRITISH COLUMBIA
UNIVERSITY OF CALIFORNIA
MONTANA STATE UNIVERSITY
NEW MEXICO STATE UNIVERSITY

\author{
UNIVERSITY OF OREGON \\ UNIVERSITY OF SOUTHERN CALIFORNIA \\ STANFORD UNIVERSITY \\ UNIVERSITY OF HAWAII \\ UNIVERSITY OF TOKYO \\ UNIVERSITY OF UTAH \\ WASHINGTON STATE UNIVERSITY \\ UNIVERSITY OF WASHINGTON
}

The Supporting Institutions listed above contribute to the cost of publication of this Journal, but they are not owners or publishers and have no responsibility for its content or policies.

Mathematical papers intended for publication in the Pacific Journal of Mathematics should be in typed form or offset-reproduced (not dittoed), double spaced with large margins. Please do not use built up fractions in the text of the manuscript. However, you may use them in the displayed equations. Underline Greek letters in red, German in green, and script in blue. The first paragraph must be capable of being used separately as a synopsis of the entire paper. In particular it should contain no bibliographic references. Please propose a heading for the odd numbered pages of less than 35 characters. Manuscripts, in triplicate, may be sent to any one of the editors. Please classify according to the 1980 Mathematics Subject Classification (1985 Revision) scheme which can be found in the December index volumes of Mathematical Reviews. Supply name and address of author to whom proofs should be sent. All other communications should be addressed to the managing editor, or Elaine Barth, University of California, Los Angeles, California 90024-1555-05.

There are page-charges associated with articles appearing in the Pacific Journal of Mathematics. These charges are expected to be paid by the author's University, Government Agency or Company. If the author or authors do not have access to such Institutional support these charges are waived. Single authors will receive 50 free reprints; joint authors will receive a total of 100 free reprints. Additional copies may be obtained at cost in multiples of 50 .

The Pacific Journal of Mathematics is issued monthly as of January 1966. Regular subscription rate: $\$ 190.00$ a year (6 Vols., 12 issues). Special rate: $\$ 95.00$ a year to individual members of supporting institutions.

Subscriptions, orders for numbers issued in the last three calendar years, and changes of address should be sent to Pacific Journal of Mathematics, P.O. Box 969, Carmel Valley, CA 93924, U.S.A. Old back numbers obtainable from Kraus Periodicals Co., Route 100, Millwood, NY 10546.

The Pacific Journal of Mathematics at P.O. Box 969, Carmel Valley, CA 93924 (ISSN 0030-8730) is published monthly. Second-class postage paid at Carmel Valley, California 93924, and additional mailing offices. Postmaster: send address changes to Pacific Journal of Mathematics, P.O. Box 969, Carmel Valley, CA 93924.

\section{PUBLISHED BY PACIFIC JOURNAL OF MATHEMATICS, A NON-PROFIT CORPORATION}




\section{Pacific Journal of Mathematics}

\section{Vol. 143, No. $2 \quad$ April, 1990}

Gustavo Corach, Horacio Porta and Lázaro Recht, Differential geometry of systems of projections in Banach algebras ................. 209

Peter Fleischmann and Jens Carsten Jantzen, Simple periodic modules of

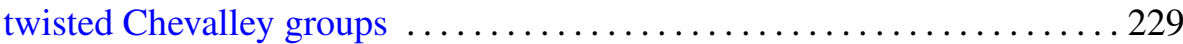

Niels Gronbaek, Amenability of discrete convolution algebras, the commutative case ...................................243

Nguyên H. V. Hung, The mod 2 equivariant cohomology algebras of

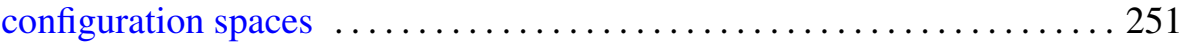

Wojciech Kucharz, Global almost analytic algebraicity of analytic sets . . . 287 John Merrill, A class of consistent anti-Martin's axioms .............. 301

Takafumi Murai, The power 3/2 appearing in the estimate of analytic

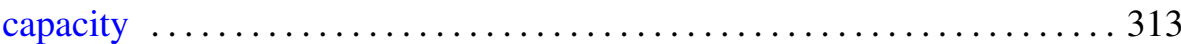

L. Panaitopol and Doru Stefanescu, On the generalized difference

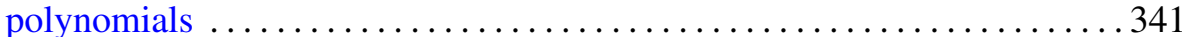

Katsuhiro Shiohama, Takashi Shioya and Minoru Tanaka, Mass of rays

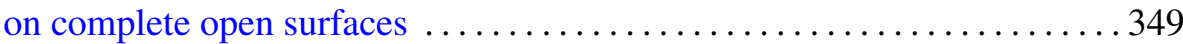

Gerhard Ströhmer, About compressible viscous fluid flow in a bounded

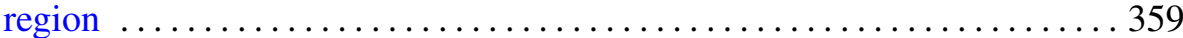

A. Ülger, Arens regularity sometimes implies the RNP 